\title{
Como narrar o banal? - Jacques le fataliste sem destino e sem juízo final
}

André Luiz Barros

Universidade Federal de São Paulo 

Sabe-se que, tal como Diderot, o Marquês de Sade foi a um só tempo um dos mais importantes escritores (ficcionista) e pensadores do materialismo (de origem epicurista) na França do século XVIII. A nosso ver, uma forma interessante de tentar entender e avaliar a obra de Sade no momento em que surgiu é vê-la como uma radicalização - ao absurdo - dessa visão materialista, a ponto de fazer do erotismo e, no âmbito do erótico, da crueldade, o fundo escondido das relações humanas - algo que, como sabemos, Freud retomará, a seu modo, cerca de um século depois do surgimento (clandestino e censurado) da obra de Sade. Note-se que esse gesto sadiano ultrapassaria uma mimese supostamente "realista" ou "naturalista" avant la lettre: ele não teria sido um autor "protorrealista", mas teria empreendido, sem a leveza cômica do chamado conto filosófico, uma espécie de mimese hiperbólica do erotismo e da crueldade como formadores de um aspecto básico e fundante da existência humana.

Propomos que o mesmo pode ser feito no caso de Diderot embora não propriamente com o erotismo ou com a crueldade dele derivada, apesar do flerte precoce do autor com o romance de libertinagem, em seu Les bijoux indiscrets, de 1748. Em Diderot, em especial no romance Jacques le fataliste et son maître (a partir de 1778), o tema hiperbolizado seria o próprio impulso mimético, a desdobrar-se em narrativa, ou seja, a busca de uma nova mimese, que desembocaria na escolha preferencial, no século XIX, do que se convencionaria chamar de "realismo moderno". Em Jacques le fataliste esse "realismo" (mais no sentido de Auerbach do que no da escola literária do século XIX tout court) é tematizado, autorrefletido e virado do avesso, mais do que praticado - essa fora a tarefa do próprio Diderot em La religieuse (176o1780), e sua defesa teórica surgira no Éloge de Richardson (1762). No Jacques, Diderot leva ao paroxismo as ideias de mimese e narrativa, paroxismo este analisado em outros textos teórico-críticos, como o Paradoxe sur le comédien, a Entretien entre d'Alembert et Diderot ou Le rêve de d'Alembert. Qual seria o elo entre esses dois Diderots do romance? É o caso de investigar. 
O rematado exagero cômico do determinismo em Jacques le fataliste et son maître - exagero fabulado entre a antiga tradição do roman burlesque (filho francês do romance picaresco) e o novo conto filosófico -, que leva Diderot a conceber que mesmo uma faculdade tão abstrata como o julgamento se deixe determinar a partir dos ecos da sensibilidade (sensibilidade até ao nível físico e corporal), acaba desaguando numa liberalização bastante ampla do agir, pois implica em um aumento do risco da coragem no aqui-e-agora, a partir da ideia de que o que quer que aconteça, qualquer que seja a consequência de determinado ato, há que aceitá-lo como "déjà écrite là-haut". O intrigante no texto de Diderot parece ser o porquê do esforço de pluralização narrativa, com o nível do narrador intervencionista, em diálogo com um suposto leitor, entremeado pela conversa de Jacques e seu amo, que se pluraliza em fala sobre os fatos corriqueiros no aqui-e-agora, que se sucedem em sua banalidade, e as interpretações dedutivas sobre o fatalismo incidindo nesses fatos e sobre as histórias do passado de Jacques, a "história de seus amores", com seu desenlace sempre adiado, sendo narrada fragmentariamente em meio a milhares de interrupções a partir daqueles outros níveis ou daquelas outras vozes.

A complexidade não é pouca, e o esforço literário é ao mesmo tempo leve, posto que satírico e ligado a um vaguear banal dos dois protagonistas, mas também hercúleo, dada a dinâmica vertiginosa entre os diferentes níveis narrativos, tendo como pseudoquestão de fundo a tese abstrata do "rouleau écrit là-haut". Por que esse esforço de pluralização radical dos níveis do narrar? E qual a relação dessa pluralização com o debate posterior, dos ro-

1 Note-se, já de início, como essa postura de positividade total se aproxima do amor fati (amor aos fatos) de Nietzsche, o qual, por sua vez, foi reaproximado (a nosso ver de forma exagerada) de uma queda inconsciente em tendência cristã, pelo filósofo canadense Charles Taylor (1997). O ciclo parece completo: o fatalismo, termo do debate religioso, via Diderot e, décadas depois, via Nietzsche, retoma seu aspecto de interseção entre os discursos religioso e, no caso, antirreligioso, já que filosófico e científico - com o desdobramento imprevisto do nível propriamente estético. 
mânticos, a partir de Friedrich Schlegel, de um supranarrador, ou seja, um eu irônico e transcendental, defendido como novo enunciador privilegiado da "poesia progressiva" romântica, segundo Schlegel, via Fichte? A questão nos parece fundamental na medida em que Jacques le fataliste, juntamente com The Life and Adventures of Tristram Shandy, gentleman, de Sterne, são modelos da tese de Schlegel sobre o romance como centro da nova "poesia" romântica.

Se certamente o supernarrador, digressivo, autorreflexivo, mestre do Witz, axial nos dois romances citados, o de Sterne e o de Diderot, surge como uma espécie de análogo literário da consciência romântica (ambiguamente individual e amplificada) que tudo englobaria e dominaria no verdadeiro abismo que se abre entre o narrador que manipula a seu bel-prazer a narração e aquele original do pergaminho que está nos céus com os desígnios do que acontece aqui na Terra (ou seja, um análogo de Deus), talvez essa extrema ambiguidade no seio do ato de narração na verdade aponte para o oposto da onisciência, ou seja, para uma aguda impotência, uma falta de controle, um vazio da narrativa. É o que tentaremos mostrar, indo contra algumas leituras desse supernarrador como síntese da reflexão romântica sobre o indivíduo e a mimese literária (uma imagem do que os românticos - leitores apaixonados de Diderot - chamariam de "gênio", conceito ele também surgido com o filósofo de Langres, entre outros).

Vejamos, primeiramente, aonde leva a cruzada antideterminista do escritor em seu Jacques le fataliste. Entendemos que, ao deslocar a questão para o foco nas contradições intrínsecas à ideia de um determinismo que suplantasse, pela via pseudocientificista, a ideia de subjetividade individual hipervalorizada - que Rousseau defendia e, a seu modo, também levava ao paroxismo -, ou seja, ao simplesmente se concentrar, em detalhe, na questão do determinismo biológico-fisiológico até mesmo no nível das ideais, projetos e julgamentos (supostamente) individuais - estratégia clara na Entretien entre d'Alembert et Diderot, como veremos 
mais adiante -, Diderot não combatia apenas o que sentia ser uma nova via de idealização do sujeito. Seguindo um pressuposto geral dos philosophes do Século das Luzes, em busca de uma totalização do pensar, ele também tocava na questão da construção da narrativa literária (do diegético). Em momento no qual a questão do destino não conseguia mais balizar o narrativo na cultura ocidental-europeia, uma outra lógica do desdobramento da história narrada parecia estar prestes a ser inventada.

Nesse âmbito, Jacques le fataliste surge quando nem o destino positivo, do heroi épico, portador do facho da coragem e da glória (a coragem, inédita, de Jacques advindo do fato de ter certeza de que sua história já estava "escrita nos céus"), nem o negativo, do heroi trágico, alvo de uma catástrofe inelutável que o engrandece, sustentam-se mais como esteios estruturais de toda e qualquer narrativa. Nesse âmbito, como se sabe, a comédia é o reverso desse engrandecimento e, portanto, o domínio dos fatos corriqueiros, baixo-eróticos, banais - esses mesmos que compõem tanto a história dos atabalhoados encontros erótico-amorosos de Jacques, quanto seu caminhar junto ao amo ao longo de todo o romance.

No limite, o que ocorre com o narrador e sua confessa impotência ("Et moi, je m'arrête, parce que je vous ai dit de ces personnages tout ce que j'en sais" (Diderot, 1973, p. 325) é a explicitação do contrário exato da onipotência: o jogo, aqui, pode ser visto como do narrador que se mantém no mesmo nível dos personagens (nível diegético), bem como no nível do próprio leitor, enquanto se entrega a seu "fluxo de consciência" narrativa avant la lettre. Nesse sentido, a análise de Jacques le fataliste deve se inserir no campo de leitura de várias estratégias diderotianas de inclusão do polo do leitor na reflexão sobre a literatura e o teatro. Tanto a célebre forma diderotiana de inserir um pseudo-si-mesmo em diálogos filosóficos (em vários textos, de Le neveu de Rameau a Le rêve de d'Alembert), quanto a farta reflexão teórico-crítica sobre um novo tipo de catarse na qual o pathos por ele 
descrito como sendo o do tableau e da condition incide sobre o leitor/espectador por vias não-aristotélicas demonstram, bem claramente, que Diderot é responsável por incluir na reflexão sobre a arte e, no caso de Jacques le fataliste, até mesmo na narrativa propriamente dita, o polo do leitor/espectador, com seu dinamismo sensível (emocional), e não com a suposição do saber poético-retórico (formal) ou mitológico (conteudístico), como era o caso no século XVII francês - época em que, como se sabe, a catarse pressupunha esses dois campos do saber já sabido (o poético-retórico e o religioso-mitológico). O que Diderot fará em textos como a Entretien sur le fils naturel ou o Discours de la poésie dramatique é deslocar a velha catarse para um novo campo do pertencer identitário (a condition, causa de empatia e deflagradora de emoção), mas com abertura para um não-saber constitutivo, o que fica mais claro no Paradoxe sur le comédien, no qual ensina-se que a obra e sua trama (os tableaux) cedem o centro do palco da reflexão ao não-sujeito por excelência: o ator. $\mathrm{O}$ ator é descrito como alguém que persegue um modelo fantasmal, que ele dominará com a experiência (e que difere de seu eu ou de sua condition, já que ele deve ser neutro ou indiferente nesses campos) e o espectador, como alguém que não tem acesso aos bastidores desse fazer ilusório. Na verdade, os homens de gênio (os artistas, no caso do teatro, o autor e os atores) têm como obrigação, quanto aos espectadores, despertar-lhes o pathos, que, desde sua raiz aristotélica, certamente possui o componente da passividade, mas também inclui a postura ativa.

Vejamos esse ponto específico: Diderot diferencia furor e possessão. Segundo ele, autor e atores manejam a mimese perseguindo "fantasmas" (modelos fantasmais) a partir do "furor", que nunca deve se confundir com "possessão". Lê-se no Paradoxe sur le comédien: "Cabe ao sangue-frio temperar o delírio do entusiasmo". Em um segundo momento, esse "entusiasmo" ou "jato" deve ser temperado com a tranquilidade e a frieza da inspiração, que lança "traços fortuitos [...] em suas obras, [...] cuja súbita 
aparição a eles próprios [autores] espanta" (Diderot, 1830, p. 11)². É quando o gênio "dirige alternadamente um olhar atento [...] à natureza e [a]o esboço (ou seja, ao modelo, como indicamos no parágrafo anterior) que produz" (Id., ibid.).

O entusiasmo do ator (ou do autor, ou seja, do gênio) 3 talvez possa ser descrito, seguindo a lógica inusitada da Entretien entre d'Alembert et Diderot, como um suplemento de energia que se insinuou em algum momento da formação do indivíduo, mas que teve de ser temperado pelo rigor da inspiração posterior (que por sua vez se descreve, a partir do que apontamos no Paradoxe sur le comédien, como um princípio organizador e harmonizador geral, totalizante e teleológico) ${ }^{4}$. Segundo essa teoria, as cordas da sensibilidade, que devem ser tangidas nos espectadores a partir do entusiasmo harmonizado da obra é, propriamente falando, uma troca ou transmissão de energia. Como ensinou Michel Delon há alguns anos, o conceito de "energia" é um conceito-chave do materialismo das Luzes, e a iconoclastia do materialista Diderot estaria em cruzar e entrecruzar domínios filosóficos e estéticos aparentemente afastados, mas que ele faz parecerem insuspeitadamente próximos. No caso, Diderot mostra como o conceito de "energia" pode ser o elo nunca encontrado entre o velho pathos de corte clássico (visto como vetor de intensidade ainda na própria

2 Cf. Lacoue-Labarthe, 2000, p. 174.

3 Percebamos que o ator como objeto de estudo indica um local intermediário entre o autor e o leitor/espectador: trata-se de um mezzo-autor, pois encarna a seu modo e, assim, cria uma expressividade própria a partir do personagem desenhado pelo dramaturgo (vide a análise da atuação de Mademoiselle Clairon no Paradoxe sur le comédien), bem como de um mezzo-espectador, pois criar "sua leitura" mediada do texto original deve "encarnar" um texto já pronto.

4 É interessante notar que a descrição de Voltaire, em seu Dictionnaire philosophique, é o exato inverso da de Diderot: a razão atua no início do trabalho do artista, não no final: "um poeta desenha primeiramente a disposição de seu quadro; é a razão, nessa altura, que lhe governa o lápis. Mas se quiser animar as suas personagens e dar-lhes o caráter das paixões, então a imaginação escalda, o entusiasmo atua; é como um cavalo de corrida que se lança impetuosamente para a meta; mas a pista foi traçada regularmente" (Voltaire, 1988, p. 80). Seria essa mais uma prova do caráter ainda classicista de Voltaire se comparado a Diderot? 
Antiguidade romana, numa obra como Do sublime, de Longino) e o novo ambiente cultural cientificista-materialista do Século das Luzes. Um autor como Diderot possibilita a transposição de fronteiras, de modo a se refletir sobre possíveis trilhas constitutivas de seu pensamento estético. Na verdade, como veremos adiante, a análise de Jacques le fataliste chega a impor tal exercício de ecletismo, dada sua constituição típica de conto filosófico, em que questões de representação estética se imbricam a problemas ontológicos. Na reflexão de Diderot sobre a arte parece surgir, mesmo que subrepticiamente, a questão do modo de atingir e de manter um certo grau de intensidade de representação do pathos. Note-se, por exemplo, o seguinte trecho do Discours de la poésie dramatique:

Dou mais importância a uma paixão, a um caráter que se desenvolve aos poucos e acaba por se mostrar em toda sua energia, do que a essas combinações de incidentes que formam a trama de uma peça em que os personagens e os espectadores são igualmente lançados de lá para cá. A meu ver, o bom gosto as despreza [...]. Eis, entretanto, aquilo que entendemos por movimento. Os antigos tinham ideias diferentes. Um encadeamento simples, uma ação praticada o mais próxima possível do desenlace [...]; uma catástrofe sempre iminente e sempre adiada [...]; discursos energéticos; fortes paixões; quadros, um ou dois caracteres pintados com vigor: eis aí todo o aparato deles. Sófocles não precisava de mais nada para transtornar os espíritos ( Diderot, 1986, p. 47).

Como se vê, Diderot defende, no teatro, o enredo simples e direto, por meio do qual os espectadores têm acesso claro aos fatos e mesmo aos atos presentes e passados dos personagens. Ataca, portanto, enredos complexos demais e reviravoltas de efeito. A energia será esteticamente mais pertinente quando concentrada - tanto em quadros (tableaux), como destacou em várias oportu- 
nidades Franklin de Matos ${ }^{5}$, quanto em catástrofes pontuais que alongam a intensidade, ou ainda em poucos personagens, porém enérgicos em seus atos, paixões ou discursos. É a resposta de Diderot ao desafio de um teatro moderno, a partir da tradição clássica das unidades de tempo, de lugar e de linguagem. Porém, o que surge aqui ligado à tradição antiquíssima a prescrever a concentração em poucos elementos intensos, muda completamente de figura no caso do romance. Diderot é obrigado a pensar sobre o novo gênero como narrativa intrinsecamente alongada e, portanto, já per se desligada da tradição das unidades, posto que o romance, àquele tempo ainda sem o prestígio cultural da tragédia ou da épica, tem tradição própria da longa concatenação linear de histórias - do Decamerão a Dom Quixote, passando pelos burlescos franceses, como Scarron e Lesage, com que Diderot dialoga diretamente no Jacques le fataliste. Ou seja, está ligado à extensão, ao desdobramento narrativo ${ }^{6}$.

Nesse ponto específico é que se compreende o interesse estético de Diderot de relacionar âmbitos díspares, como uma filosofia da ação, o fatalismo, as ciências e a arte do encadeamento narrativo: por trás da ação deve haver um interesse reflexivo a respeito da lógica da concatenação, da ideia de causa eficiente, de acaso, de unidade do eu diante dos múltiplos fatos corriqueiros (o que Starobinski chama da "certeza da unidade do eu" em Jacques le fataliste: a paixão pelo vinho, para Jacques, ou a caixa de rapé, para seu amo, junto com vários outros hábitos banais, dão a certeza da unidade do sujeito ao longo de episódios virtualmente infindáveis).

5 Cf. Franklin de Matos, 2001.

6 Lembremos, nesse ponto, que aproximações entre o romance e a épica são talvez inexistentes nesse momento de legitimação do novo gênero por um motivo que nos parece simples, embora nem sempre lembrado (por nós que, hoje, conhecemos a reflexão de um Lukács sobre a relação entre a épica antiga e o romance moderno): como aproximar romance e épica num momento em que, na ampliada querelle entre anciens et modernes, o partido dos antigos se nega a valorizar o novo gênero, e o partido dos modernos tem consciência de que ele instaura um novo tipo de mimese, menos elevada e, portanto, incomparável à da épica grega? 
Portanto, em Jacques le fataliste não se trata mais de pensar o foco concentrado (ou deflagrado pontualmente, para criar tensão duradoura), típico do teatro clássico, mas de pensar uma nova lógica da narrativa necessariamente alongada, relacionando-a a modos de pensar as ações humanas, sua concatenação e seus desdobramentos verossímeis (ou seja, uma espécie de ontologia ética projetada no plano estético). Obviamente, a diferença em relação ao otimismo ou positividade de base da épica clássica nos parece clara: não se trata mais de figurar o herói como portador do destino vencedor de um povo, mas de flagrar pseudo ou anti-heróis "baixos", um criado, um originel (ou seja, uma figura do povo), interessados em seu caminhar contingente, banal, despegado das altas rodas aristocráticas, como fora o caso nos romances picarescos e na pseudopícara do Quixote.

No caso de Jacques, as ideias de causa eficiente ou do "rolo de pergaminho escrito desde sempre lá em cima" (le rouleau écrit là-haut), núcleo do simplório fatalismo que Jacques aprendeu de seu capitão, servem para separar, a seu modo atabalhoado (ou seja, pícaro-burlesco), o discurso hipotético-dedutivo dos fatos corriqueiros e das ações possíveis diante desses fatos. Mas cada fato corriqueiro, banal, ao longo dos vários episódios que se entremeiam à narrativa de seu passado (ela também salpicada de fatos corriqueiros) obriga-o a reunir novamente o nível abstrato da dedução (da teoria fatalista) ao aqui-e-agora concreto e banal - já que sua ação junto com o amo não tem nada de sublime, sendo ela, como no caso de Dom Quixote e mesmo dos romances picarescos, uma ação "baixa". Essa reunião é feita à moda de Jacques, pela qual nacos da teoria (do fatalismo) são usados a seu bel prazer (por exemplo, de forma geral o fatalismo permite uma coragem cega, pois se tudo já está escrito de antemão... Essa dedução é, ela mesma, contingente, e não rigorosa ou filosófica). A disjunção entre dedução hipotética e teórica, de um lado, e prática e contingente, de outro, expõe o vão de absurdo entre um nível e outro. 
Um modo de começar a compreender a relação entre esse jogo que oscila, às vezes vertiginosamente, entre o leve e banal e o dedutivo-abstrato, é referir-se à análise de Jean Starobinski de um pequeno trecho da Entretien entre d'Alembert et Diderot. É a passagem em que o Diderot do diálogo descreve a formação - biológica e fisiológica - do indivíduo d’Alembert a partir das moléculas de sua mãe, Madame de Tencin, e de seu pai, o militar La Touche. Starobinski lembra que a história surge depois de Diderot descrever o ciclo de transformação do mármore em carne a partir da destruição e pulverização de uma estátua do famoso Falconet, o pó de mármore se misturando à terra, onde verduras no futuro nasceriam para, enfim, alimentar o homem. A ideia do encadeamento dos acontecimentos naturais, ou seja, do próprio fatalismo, no sentido usado por Diderot no romance (um pouco diferente do da polêmica religiosa), já inclui, de saída, o homem, sua carne e sua ação, por mais mecânica ou autômata que seja. Aliás, trata-se da inclusão do debate filosófico das causas eficientes (Leibniz ou Berkeley, mas também Malebranche e Hume) e do panteísmo cientificizado, ou seja, ateu (Espinosa).

Em seu Dictionnaire philosophique, Voltaire dá a senha para entendermos tanto a linhagem de pensamento de onde Diderot deve ter extraído seu interesse quanto o caminho de união entre filosofia e estética da narrativa. No verbete "Cadeia de acontecimentos", cita o fatalismo logo de primeira e relaciona essa noção extraída do domínio eclesiástico com o velho destino dos épicos e trágicos gregos. "Os acontecimentos estão encadeados uns aos outros por uma fatalidade invencível: é o Destino que, em Homero, está acima do próprio Júpiter" (Voltaire, 1988, p. 30).

Para podermos examinar com maior cuidado o porquê dessa aproximação entre fatalismo e estrutura mitopoética clássica, voltemos a Starobinski e vejamos sua análise do discurso do Diderot do diálogo sobre a gênese corporal de d'Alembert. O crítico suíço aponta a estratégia discursiva do autor de partir de um ser (pode- 
ria ser um acontecimento) presente, no aqui-e-agora, ou seja, a presença corporal de d’Alembert, para só então refazer discursivamente sua formação.

O recurso ao exemplo atual, a argumentação ad personam, a evocação da contingência de d'Alembert, tudo isso dá à argumentação hipotética o seu lastro de evidência, e faz chegar a dedução ao indivíduo presente e ao momento presente. $\mathrm{O}$ aspecto aventureiro da conjuntura molecular é compensado (e mascarado) pela realidade do homem de d'Alembert (Starobinski, 2012, p. 259).

Parece haver aqui uma intuição aguda, que se desdobra em observação sobre o próprio Jacques le fataliste, na qual Starobinski aponta a impossibilidade lógica de uma narrativa se iniciar tendo como base a ideia de que tudo está escrito de antemão em um pergaminho nos céus.

Assim que se postula o encadeamento necessário, uma questão se coloca: por onde começar? Em boa lógica, seria necessário poder remontar ao momento em que tudo foi escrito lá no alto, seria necessário reunir-se à causa primeira, o decreto original da Providência. [...] Esse conhecimento estando proibido a nós, tomar-se-á seu ponto de partida onde bem se entender. [...] A primeira página de Jacques le fataliste nos propõe, à escolha, toda uma série de começos - pluralidade que tem por efeito nos persuadir que nenhum desses começos é um verdadeiro começo... Não se começa jamais senão in media res (Id., ibid.)

Já estamos, nesse ponto, no âmbito da imbricação entre uma “teoria (ou filosofia) do acontecer natural e humano" e uma reflexão sobre como narrar esse acontecer. Podemos supor que o século de Diderot, mas também o de Rousseau, como sabemos, foi o momento em que às escatologias pagãs (na arte: a questão do destino) e católicas tentou-se substituir a reflexão sobre o começo. "Nada sai do nada", diz d'Alembert no momento imediatamente 
anterior ao início da narração de Diderot sobre sua origem molecular a partir do encontro de seu pai e de sua mãe. Não nos esqueçamos que o romance A vida e as aventuras do cavaleiro Tristram Shandy, modelo do Jacques le fataliste, tem como fio condutor dos desvios e desvãos digressivos infindáveis a tentativa de narração do gênese de Tristram. O livro começa com o intercurso entre seus pais para produzir o protagonista - é o que Tristram chama de começar "Ab ovo". Depois da passagem sobre a gênese de d'Alembert, no mesmo diálogo, surge a reflexão narrada sobre o nascimento de um pinto em um ovo.

Só nos resta um desses partidos a tomar; imaginar na massa inerte do ovo um elemento escondido que esperasse seu desenvolvimento para manifestar sua presença, ou supor que esse elemento imperceptível ali se insinuou através da casca em um instante determinado do desenvolvimento. Mas o que é esse elemento? Ocupava espaço, ou não ocupava nenhum? [...] Para não admitires uma suposição simples que tudo explica - a sensibilidade, propriedade geral da matéria ou produto da organização -, renuncias ao senso comum, e precipitas-te em um abismo de mistérios, de contradições e de absurdos?

Como se vê, no Entretien entre d'Alembert et Diderot o exercício de compreensão e narração de uma suposta (ou construída) origem deságua na ideia de um ciclo natural infinito de energia, em que sensibilidade engendra sensibilidade, ou seja, sensibilidade estimula (ou entusiasma) sensibilidade, em suma, em que a energia circula, move e dá lugar até as produções humanas mais

7 «Il ne vous reste qu'un de ces deux partis à prendre; c'est d'imaginer dans la masse inerte de l'œuf un élément caché qui en attendait le développement pour manifester sa présence, ou de supposer que cet élément imperceptible s'y est insinué à travers la coque dans un instant déterminé du développement. Mais qu'est-ce que cet élément ? Occupait-il de l'espace, ou n'en occupait-il point ? [...] pour ne pas admettre une supposition simple qui explique tout, la sensibilité, propriété générale de la matière ou produit de l'organisation, vous renoncez au sens commun, et vous précipitez dans un abîme de mystères, de contradictions et d'absurdités ». (Diderot, 1965, p. 52-53). 
elevadas, menos materiais, como as ideias e as artes. Em Rousseau, como se sabe, o mito da Idade do Ouro do homem ainda selvagem é mais um "mito da origem" em sua estratégia teórico-reflexiva, política, do aqui-e-agora, do que uma exaltação neocristã (apesar dos aspectos cristãos que sua obra tomará). Para Diderot e para Rousseau cabia o esforço de decidir ou produzir um começo - ou pensar sobre o fato de um começo mítico ser exercício teórico inescapável - para uma modernidade que se instaurava modificando, retroativamente, toda a visão do passado, do presente e do futuro, assim fazendo desaparecer as antigas concatenações que organizavam culturalmente a relação entre o homem ocidental e o tempo (tanto as greco-romanas quanto a cristã). Neles parece já haver a intuição de que na modernidade o que é possível de fazer são apenas recortes teóricos de começos - pensar em uma origem única seria retornar ao mito.

A questão do começo arbitrário - decidido pelo autor - surge desde a primeira linha de Jacques le fataliste. Seguindo a sutil indicação de Jean Starobinski, no primeiro plano da narrativa encontra-se a presença física, contingente, no aqui-e-agora como origem e fim de qualquer discurso, por mais abstrato e hipotético-dedutivo que ele seja. O banal do momento presente sempre intervém, como se nota num primeiro episódio, no início vertiginoso do romance. Flagra-se Jacques e seu amo extraviados porque este último dormiu ouvindo o início da história dos amores do criado; surge, de repente, um cirurgião com uma moça na garupa de seu cavalo; quer demonstrar que Jacques tem razão ao descrever o joelho como uma parte por demais complexa da anatomia. Em vez dessa demonstração médico-fisiológica, o "baixo corporal", o erotismo banal surge abruptamente com a queda da mulher, que prende um pé na sela do cavalo e fica pendurada de ponta-cabeça; sua saia e as anáguas caem, deixando à mostra pernas e um pouco mais; o narrador diz não saber se Jacques começara seu exame por abaixar as anáguas ou por livrar o pé preso da mulher; o erotismo da cena culmina com a palavra "cul", no 


\section{fim do discurso de Jacques à moça, explicando-lhe este que estava escrito nos céus que eles veriam aquela parte específica de seu corpo àquela hora e naquele lugar ${ }^{8}$.}

8 A questão do banal, do contingente radicalizado (ou seja, daquilo que, não parecendo essencial, no entanto muda o rumo da ação, e pode fazê-lo a qualquer momento - da vida ou da narrativa) remete-nos a uma reflexão sobre o Diderot pensador (e praticante) de um protorrealismo ocidental, em textos reflexivos como Eloge de Richardson e literários como La religieuse. Trata-se de pensar a bifurcação entre o Diderot que, ao elogiar Richardson, elogia todos os detalhes realísticos da narrativa do romance, em especial os banais e periféricos, e o Diderot de Jacques le fataliste e do Paradoxe sur le comédien, que elogia o contrário, ou seja, o vazio insensível da criação mimética. Penso que um traço une os dois Diderots: ele parece ter empreendido uma revolução estética ao substituir a tripartição elevado/médio/baixo do classicismo, vigente por muitos séculos, pela ideia de centro/periferia. Trata-se de valorizar o periférico como intrinsecamente importante ou fundamental para o central: o romance seria o campo próprio em que os detalhes periféricos seriam, pela primeira vez nas artes, valorizados como elementos a modificar os rumos da ação (ou do indivíduo) que está no centro de atenções. Se seu elogio dos gestos e dos gemidos, no teatro, como nos mostrou o prof. Franklin de Matos, serve para combater ou relativizar a exclusividade da palavra retórica, seu elogio dos detalhes banais, em literatura (em Richardson e em seu romance richardsoniano, La religieuse), bem como na pintura, em que o baixo-burguês de Greuze e Chardin é o centro de suas preocupações (contra os pastéis de Watteau ou Fragonard), aponta para a valorização do aparentemente pequeno e banal na transformação do quadro central: as várias páginas de descrição do quarto ou das vestimentas de Clarissa Harlowe por Richardson são tão importantes quanto as descrições de seus humores, atos, ideias ou sentimentos. Se no classicismo havia uma proibição da passagem ou da mistura entre alto e baixo, a modernidade, segundo Auerbach, seria fruto exatamente dessa inédita mistura. Diderot parece indicar que nessa modernidade, a relação alto/baixo se planifica em relação centro/periferia, divisão pela qual a periferia, na mimese, é tão importante para o desenrolar da narrativa, do enredo, quanto o centro. No "reino das particularidades", o romancista acolhe - às vezes de forma obsessiva e detalhista - singularidades quaisquer, com o fito de compor particularidades mais representativas. A referência à dinâmica singular-particular-universal, que Lukács usa para pensar o papel do romance, nos parece um dos modos de começar a pensar sobre a transformação em curso. Pensemos especificamente na importância das interrupções dos fatos corriqueiros ou banais no Jacques le fataliste: eles influem, sem nenhuma hierarquia de importância, tanto nas ideias abstratas de Jacques e de seu amo (sobre fatalismo), quanto no rumo de seus atos concretos no aqui-e-agora, com direito a intervirem no rumo da narrativa do que chamarei, mais adiante, de supernarrador, ou seja, o narrador intervencionista. Entre o texto original ao qual esse narrador tem acesso e sua suposta e propalada onipotência de mudar o rumo dos fatos e das ações da trama surge a reflexão sobre como essa trama (que é do romance e de nossas vidas) se organiza a partir do pequeno, do periférico, do aparentemente desimportante, tanto quanto a partir das grandes ideias e das sempre limitadas vontades. Ou ainda, como o universal, o abstrato, o filosófico é composto (no sentido de constituído e, portanto, impossível de ser pensado separadamente) a partir do singular-banal, do periférico. Nesse início de reflexão que temos desenvolvido, utilizamo-nos de um romance contrário a qualquer protorrealismo literário (Jacques le fataliste) para pensar o protorrealismo propriamente dito (patente, por exemplo, em La religieuse). 
Há também nesse começo, é claro, como ao longo de todo o romance, as intervenções do narrador, remetendo para a própria questão da lógica do narrar, ou ainda, da necessidade de organização sequencial, de encadeamento. "Vous voyez, lecteur [...], qu'il ne tiendrait qu'à moi de vous faire attendre un an, deux ans, trois ans, le récit des amours de Jacques" (Diderot, 1973, p. 36). A rematada leviandade do narrador aponta para uma aporia intrínseca da narrativa, num momento em que os modelos greco-latinos humanistas, bem como o próprio arcabouço cultural bíblico e escatológico cristão, desapareciam do horizonte cultural, obrigando a forjar um novo modo concatenado de narrar. Isso porque se trata de um modo de narrar sem destino, sem o "juízo final" cristão, sem motivações ligadas à honra e à coragem clássicos (desde Homero), sem a motivação da glória no além-túmulo, bem como sem o peso do fantasma da culpa vigiando os atos presentes a partir da futura agonia final - aquele momento em que os libertinos deveriam, como os bons cristãos, se arrepender e, com isso, mudar o sentido de toda a vida pregressa, rumo a uma imagem sacralizada no futuro -, em suma, um modo de narrar em meio ao mundo no qual a relação do homem com seu tempo, com o passado e com o futuro mudava vertiginosamente. Não admira, portanto, que a narrativa tivesse que ser repensada em sua própria lógica e necessidade interna. É nesse momento que surge um romance - Jacques le fataliste - que simplesmente expõe o vazio da possibilidade de decisões do suposto narrador. Nele, diferentemente do caso dos romances de Sterne ou de Cervantes, os dois grandes modelos do romance de Diderot - e contraditoriamente com o próprio final do romance -, o narrador diz poder mudar a qualquer momento uma narrativa que na verdade estaria sendo copiada de um original ao qual só ele tem acesso.

O final do romance mostra bem a fusão entre a vertente reflexiva científica e o campo propriamente literário: o "rouleau écrit là-haut" é esse original que, na verdade, replica ou desdobra as obras-modelo (além de Sterne e Cervantes, há ainda Rabelais, o 
abade Dulaurens, autor de Le compère Mathieu etc.). A "huitiaine" (semana) durante a qual o narrador vai reler o original para meditar sobre o final a ser contado expõe, pela última vez, e de forma magistral, o vazio da decisão: ele tem que avaliar se um dos parágrafos do fim da história é autêntico ou se é um plágio (a palavra "plagiat" é nova9 , num momento em que o próprio Diderot apenas inicia uma reflexão moderna sobre o tema da propriedade e os direitos autorais modernos e de corte capitalista $\left.{ }^{10}\right)$.

Como percebemos, portanto, o supernarrador da ironia romântica, no caso de Jacques le fataliste, como defendemos, é ambiguamente e a uma só vez supernarrador (pois pode se decidir sobre cada cena) e narrador completamente submetido a um manuscrito original - bem como aos modelos que ameaçam ser alvo do plágio desse original. Veja-se que esse Jano de duas faces indica, ao mesmo tempo, a liberdade (certamente excessiva, talvez impossível) de poder decidir as vias da mimese narrativa - a liberdade do autor, do gênio, que no instante do perecimento dos modelos greco-latinos e cristãos, é ao mesmo tempo uma dádiva e uma ameaça de abertura sem limites, de desfazimento - e as balizas estritas, rigorosas que o autor-gênio terá que inventar para si mesmo, a partir de um modelo fantasmal que ele criará mentalmente para refrear e harmonizar seu entusiasmo. Se o ambíguo e mesmo cínico prefácio de La religieuse oferece o único momento vazio exposto (vazio da mimese) do romance de representação literária fechada na prisão do detalhismo à la Samuel Richardson - e se o prefácio de La nouvelle Héloïse, de Rousseau, tem a mesma função (ou seja, se os prefácios são locais extradiegéticos onde a questão do vazio da decisão mimética pode ser exposta) -, em Jacques le fataliste esse vazio se expõe a cada momento, a cada passo dos personagens e do narrador, nesse verdadeiro (e burlesco) tratado mimético sobre a mimese.

9 "Plagiat" aparece na quarta edição do Dictionnaire de l'Académie Française, de 1762. 10 Cf. Lettre sur le commerce de la librairie, de Diderot. 


\section{Referências bibliográficas}

DIDEROT, D. Discurso sobre a poesia dramática. Trad. Franklin de Matos. São Paulo: Brasiliense, 1986. . Entretien entre d'Alembert et Diderot; Le rêve de d'Alembert; Suite de l'entretien. Paris: Garnier-Flammarion, 1965. . Jacques le fataliste et son maître. Paris: Gallimard, 1973. . Paradoxe sur le comédien. Paris: A. Sautelet et Cie., 1830 (consultado em www.bnf.fr/gallica).

FRANKLIN DE MATOS, L. F. O filósofo e o comediante. Belo Horizonte: Ed. UFMG, 2001.

LACOUE-LABARTHE, P. A imitação dos modernos. São Paulo: Paz e Terra, 2000.

STAROBINSKI, J. "Le philosophe, le géomètre, l'hybride" [1975]. In: Diderot, un diable de ramage. Paris: Gallimard, 2012.

TAYLOR, C. As fontes do Self. São Paulo: Loyola, 1997.

VOLTAIRE. Dicionário filosófico. São Paulo: Nova Cultural, 1988 (Col. "Os Pensadores"). 
